\title{
Developing Concrete Research Proposals and Facilitating Self-Directed Learning via Concept Mapping
}

\author{
Keetam D. F. Alkahtani \\ Department of Special Education, College of Education, King Saud University, Riyadh, KSA \\ Email: kalkahtani@ksu.edu.sa
}

Received November 8 $^{\text {th }}$, 2012; revised December 10 ${ }^{\text {th }}, 2012$; accepted December $24^{\text {th }}, 2012$

\begin{abstract}
Self-direction in learning and writing viable research proposals are considered by higher education institutions as essential skills for graduate students to start their careers as researchers. This is an evidence-based practice study focuses on the use of concept mapping to facilitate self-directed learning and enhance research proposal writing in teacher education. An action mixed methods research design was used in this study with quantitative and qualitative data. Participants were 29 graduate students who were enrolled in a core course aimed to provide learners with an in-depth understanding of research methods. All students, at the beginning of the course, were asked to write a research proposal and complete the Self-Directed Learning Readiness Scale (SDLRS). They then were given training in the use of concept mapping technique throughout the course to develop research proposals. Students' scores prior to and after the intervention were compared. Results indicate that students developed significantly more concrete research proposals, and displayed higher scores at post-intervention assessment. Findings of this study value and support the use of concept mapping to provide students with a comprehensive understanding of the knowledge of their area of study as they reflect on every element of their proposals.
\end{abstract}

Keywords: Concept Mapping; Meaningful Learning; Self-Directed Learning; Research Proposals; Action Research; Higher Education

\section{Introduction}

\section{Conceptual Framework}

We usually are unaware of our beliefs, values, and assumptions about how knowledge is created. Objectivity cannot be isolated from subjectivity, and the connection between them constructs our knowledge. Thus, we learn through collective reflection and action (Gee, 2005; Novak, 1998; Roberts \& Dick, 2003). Authority gaps between educators and students might lead students to undervalue their own knowledge and abilities. Narrowing gaps in authority elevate the worth of students' investigative skills, practical and experiential knowledge. This assumption is in line with action research philosophy which views the research as shared ownership and the researcher, or research team, should not work for or about the participants, but rather with them (Denzin \& Lincoln, 2005). Participants, therefore, co-construct knowledge through shared experience and reflection (Roberts \& Dick, 2003). I view action research, which is the method that I adopted for this study, as a process that pay attention to issues of experiential knowledge and empowering participants to change some part of their circumstances or experiences for the better. Eventually, as a teacheraction researcher, this will led me to better understand and improve my practice. It will also empower my students to examine their knowledge and gain a sense of their own understanding and needs as they learn. Critical constructivist paradigm is the philosophy that I have adopted in this research. This paradigm theorizes that all knowledge is socially constructed and our knowledge is co-constructed by our understanding and experiences with the social world. Thus, there is neither one truth, nor one knowledge (Bergman, 2008; Carr \& Kemmis,
1983; Charmaz, 2006). The idea of multiple realities, truths and ways of knowing was a key in the development of this research.

\section{Research Purpose}

Teaching a course of research design is challenging. Most of my students, even when they have the ability to write a good course paper, they lack the ability of writing a clear, structured, articulate and persuasive proposal. Writing a viable research proposal requires knowledge, wisdom, and reflective thinking. The state of my students' learning is best described in one of Eliot's most famous quotes "Where is the life we have lost in living? Where is the wisdom we have lost in knowledge? Where is the knowledge we have lost in information?” The quote portrays the relationship between life, wisdom, knowledge, and information. This relation is the origin of the datainformation-knowledge-wisdom hierarchy (also known as the DIKW pyramid). According to the DIKW sequence information is build from data. Yet, information is not a collection of data. Attributing meaning to data within context will be crucial to translate data to information. Understanding of the relations between data provides the foundation of information needed to answer who, what, where, and when questions. Knowledge is constructed from information, but it is not a collection of information. Relations between information can be stated in patterns which have the potential to represent knowledge. Understanding of the relations between patterns is fundamental to understand those patterns and generate knowledge that can be used for answering how questions. Wisdom arises from knowledge, but it is something much more than a collection of knowledge. Understanding of the founding principles for the 
patterns is a vital step towards achieving wisdom that will serve in answering why questions (Ackoff, 1989; Bellinger, 2004; Rowley, 2007; Zins, 2007). Meaningful knowledge is required to evaluate understanding and grasp the truth which is the value we extract from wisdom. Meaningful knowledge can be obtained via meaningful learning (Novak, 1998). In this action research, I utilize self-directed learning (SDL) and conceptual approach in conjunction with concept maps to endorse meaningful learning. Promoting the development of meaningful learning is crucial to enjoy and understand research process. Meaningful learning might lead my students to a deeper understanding and possibility of benefit from the experience of doing research. As my students are beginning their journey into the research arena, self-directedness in learning and knowing more about their own knowledge construction process can have a major impact on their ability and skills as researchers. The purpose of this research is to promote dialogue among graduate faculty to better understand the problems graduate students have with writing viable research proposals, and to investigate some practical solutions. The overarching research question used to frame this action research was: Do using concept mapping promote self-directed learning (measured by Self-Directed Learning Readiness Scale, Guglielmino and Associates, 2004) and influence the production of a viable research proposal?

\section{Self-Directed Learning}

In learning, self-direction has two aspects. The first is as a goal of education. Individuals are not equally self-directed. Educational practice should be designed to develop or enhance the learner's ability to be self-directed. Developing self-direction is essential for success in understanding one's own learning needs, as well as identifying goals for the learning and the proper resources needed to accomplish these goals (Candy, 1991). Therefore, individual's ability to be self-directed assists in the natural progression of learning as lifelong quest for knowledge which is a highly desirable goal of education.

The second aspect of self direction is as method of learning. In this method of learning, the learner willingly teaks higher levels of responsibility and control over her own learning experience and eventually will arrive at a point where her learning is completely independent (Candy, 1991; Knowles, 1975). There are three basic models of how to develop self direction as method of learning: linear, interactive, and instructional. The linear model (Knowles, 1975) is very linear in nature and involves steps in a linear process. The teacher must let the learner assume most of the responsibility for planning and completing the learning task and learn at her own pace (Knowles, 1975). The interactive model (Garrison, 1997) is based on the premise that the natural state of learning is through inquiry and does not always follow a set pattern. The teacher provides guidance with locating or organizing resources and assessing learning. However, the achievement of specific goals by planning, implementing, completing, and evaluating the learning task is the learner's primary responsibility (Garrison, 1997). The instructional model (Grow, 1991) consists of instructional methods and assignments which can be incorporated into the learning environment to aid the learner in becoming more self-directed. Learners, according to this model, can be identified as: Dependent learners (play a very passive role in their learning, and fully dependent on the teacher), Learners of moderate selfdirection (willing to take part in their learning), Learners of intermediate self-direction (have the ability to perceive themselves as active participants in the process of their learning), and learners of high self-direction (have the ability, with little or no help from a facilitator, of planning, carrying out, and evaluating their own learning) (Grow, 1991). In these three models, regardless of their structure, the major goal is to aid learners in becoming more self-directed and the role of the teacher is a facilitator of the learner's learning experience. Building on the promising practices of the literature, my primary role as a teacher-action researcher was providing my students with the skills necessary to plan, implement, and assess their own learning.

\section{Meaningful Learning and Concept Mapping}

Ausubel's assimilation theory focused on the process through which humans acquire knowledge. The main notion of this theory is centers on representing learning as either rote learning by memorization or meaningful learning by "choosing to relate new knowledge to relevant concepts and propositions” (Ausubel, 1968: p. 7). Ausubel premise is that the individuals' prior knowledge is highly important to their ability to assimilate new information and learning in a meaningful context to gain a deeper, most lasting and more complex understanding. $\mathrm{He}$ stated, "the most important single factor influencing learning is what the learner already knows. Ascertain this and teach him accordingly" (1968: p. iii). Ausubel's view backed by constructivism which is a theory had its beginnings with learning ideas from John Dewey who draw attention to the use by learners of their individual experiences to make sense of novel information they were exposed to and also the benefits of social interaction for the learner. The work of Maria Montessori, Jean Piaget, and Lev Vygotsky have influenced constructivism as a learning theory that could be used to develop new cognitive structures that are more sophisticated and allow learners to increasingly organize new knowledge (Lambert et al., 2002). From a constructivist point of view, prior knowledge influenced what new ideas learners would be able to grasp and how they would interpret that new information. Therefore a person's conceptualization of new knowledge is individual because of the prior experiences and memories she had, including emotions and feelings associated with the experiences. Concept mapping, within this framework, is an effective teaching and learning strategy to assimilate the previous knowledge with newly introduced concept and therein derive meaningful learning. In the early 1970s Joseph Novak and his colleagues at Cornell University presented concept mapping as a tool to represent knowledge structures. Novak, building on Ausubel's assimilation theory, created concept mapping as visual representations of concepts and the meaningful relationships that exist among or between related concepts in the form of propositions. Thus, a concept map is a form of knowledge representation and will reflect the learner's knowledge structure in a given topic, subject, domain or area under discussion and search (Novak, 1977). The phrase concept maps has been used interchangeably with mind maps and knowledge maps. However, Cañas and colleagues distinguished concept maps from other mapping systems by their theoretical basis in Ausubel's assimilation learning theory and constructivist epistemology, their semi-hierarchical organization, the use of unconstrained and meaningful linking phrases, and the way concepts are defined (Cañas et al., 2003: p. 13). Given that a concept map is a two-dimensional 
diagram that displays relationships between concepts through using linking words, hierarchically structured with progressive differentiation, from general to specific. When these relationships are made, learners can draw on what they know and reshape it in new and meaningful ways. Therefore, concept mapping which "developed specifically to tap into a learner's cognitive structure" is effective metacognitive mechanism that increases learner knowledge of a particular topic (Novak \& Gowin, 1984: p. 40). Seeing that the literature stresses the importance of the conceptual mapping, I designed my courses to introduce students to this method of organizing and forming information into meaningful learning.

\section{Method}

\section{Participants}

A total of twenty-nine graduate students who were enrolled in a core course titled Research Design and Its Application in Special Education (SPED 520). Fifteen students were enrolled in the first semester and fourteen were enrolled in the second semester of the academic year 2011-2012.

\section{Design}

Integration of qualitative and quantitative approaches (mixed-methods) in a participatory action research (PAR) with pre and post-evaluations.

\section{Data Collection}

The quantitative data consisted of three parts: 1) students' results at the Assessment Rubric for Research Proposal (ARRP); 2) students' scores on Self-Directed Learning Readiness Scale (SDLRS); and 3) students' responses to anonymous 29-item course and faculty evaluation survey that used a 5-point Likert rating scale $(1=$ strongly disagree, $5=$ strongly agree $)$. The qualitative data included analyses of students' concept maps, and semi-structured individual and focus groups interviews.

\section{Procedure}

This action research is as much about process as it is about product. The process of this study is relatively simple and consisted of the Plan-Act-Observe-Reflect research cycle (Creswell, 2008; Mertler, 2006; Taylor et al., 2008). Students were co-researchers who actively involved in generating and collecting information (Mordock \& Krasny, 2001). Evidence for the problem was gathered from group discussions and results of ARRP and SDLRS. Results of the pre-assessment were considered the baseline data and also used to shape the plan of action. The plan of action is to promote self-direction in learning by employing strategies which aid learners in learning how to learn and think for themselves. I utilized concept mapping strategy as it is aim is aiding learners during their learning process. Essential elements of implementing the plan were weekly reflection, focus groups interviews, constructing concept maps, and tracing the progress of the research proposals of the student. At the end of the course, final research proposals were assessed using the ARRP. Students were asked to complete the SDLRS and the SPED 520 course and faculty evaluation survey.

Implementation of my action plan requires learners to be cognizant of the concept mapping process. Therefore, to ensure familiarity with concept mapping, all students participating in this study were introduced to this technique by receiving instruction on how to develop a concept map in a two-hours session. This training was presented, in the second session of the course, based on Novak and Gowin's recommended strategy of teaching concept mapping construction to learners (Novak \& Gowin, 1984: pp. 32-34; Novak, 1998: p. 227). Training material consisted of two sections. The first section included a conceptual framework and illustration of concept mapping technique and instructions on how to create a concept map. The second section included an article of the students' own choice so the students use it to create a concept map. The article selected by the students to reduce unnecessary cognitive overload caused by unfamiliar content. This allowed them to focus on concept mapping practice itself. I, at the end of the training session, asked the students to generate concept maps for their research proposals. These maps were used throughout the course to develop research proposals. Concept maps should be extensions of the learner's natural cognitive chunking and linking, therefore I asked my students to revise and reflect on their maps weekly. I was aware of the fact that with no controls on the students this would be "soft" data, but I believe that the personal nature of the concept mapping manifested itself by establishing consistent differences between learners. I also believe that comparing students to another on the basis of their concept maps would not be fruitful as I was not looking for one pattern among learners but rather for consistent pattern exhibited by an individual.

As the idiosyncratic nature of self-directed learning is preserved by allowing learners to pursue their own paths, I wanted my students to have enough freedom to apply their concept maps in whatever way they will find helpful and fit their needs. I informed my students that the strength of their concept map is what the map meant to them, not what someone else understood from it. I also advised them not to compare their concept maps to anyone else's, but rather use these maps to their advantage by linking new information, from the course lectures and reading assignments, with their previous knowledge. I asked my students to hand in a copy of their concept map in progress before each lecture. By the end of the course, I collected thirteen concept maps from each student, the first and last maps were considered as the pre and post-intervention concept maps.

\section{Credibility}

Credibility (validity and reliability) of knowledge acquired from an action research is immediately recognized as workable and effective in solving problems or developing practice by those in similar situations (Somekh, 2006). Enhancing the credibility of action research can be acquired by using datatriangulation (Creswell, 2008; Mertler, 2006; Taylor et al., 2008; Teddlie \& Tashakkori, 2009). In this study triangulation of data sources include quantitative data (students' scores on ARRP and SDLRS, students' responses to course and faculty evaluation survey) and qualitative data (multiple interviews, analyses of students' concept maps).

\section{Results and Discussion}

Data from both the first and the second semesters were merged to represent an accurate representation of SPED 520 
praxis. Quantitative data were analyzed using the Statistical Package for the Social Sciences, SPSS-20. The paired-sample $t$ test was used to quantify the effect of the concept mapping strategy on students' production of viable research proposals as measured by ARRP. The mean of the pre-intervention scores were compared with the mean of the post-intervention scores. The results indicated that the two scores were significantly different $(t=53.219, p=0.000)$ suggesting that students displayed significantly higher post-intervention scores at the 0.01 level compared to their pre-intervention scores on ARRP. Effect sizes was (9.88) by Cohen's d and (0.99) by effect-size $r$ for paired data. Both are large effect sizes. Results of the analysis are summarized in Table 1 and Figure 1.

To verify if there was a difference between the pre-intervention and the post-intervention scores on the SDLS the pairedsample $t$ test was used. The mean of the pre- and post-intervention scores were compared. The results revealed that the two scores were significantly different $(t=2.626, p=0.014)$ which signify that the students demonstrated significantly higher post-intervention scores at the 0.05 level compared to their pre-intervention scores on SDLR. Effect sizes was (0.5) by Cohen's d and (0.18) by effect-size $r$ for paired data. Both are medium effect sizes. Results of the analysis are presented in Table 2 and Figure 2.

Pearson's correlation coefficient was conducted to evaluate the relationship between students' level of self-direction in learning and their ability of writing viable research proposals. A strong positive correlation was found between students' scores on the SDLS and their scores in the ARRP, for the pre-intervention' scores was $(r=0.692, p<0.0001)$ and for the postintervention' scores was $(r=0.670, p<0.0001)$. This correlation shows a significant relationship at the 0.01 level between the students' scores on the SDLS and ARRP in both the preand post-intervention. Table 3 and Figure $\mathbf{3}$ present this results.

Of the 29 participants, 27 completed the anonymous standardized university evaluation survey. This course and faculty evaluation survey compare faculty performance with the average of other faculty members in the department, college, and university. Analysis of the group mean score revealed that SPED 520 course rating were higher than classes throughout the department, college, and university. Group means are shown in Table 4 and Figure 4.

It was not possible to correlate course evaluation scores with ARRP and SDLRS scores, as the results were obtained without identification.

Qualitative data were analyzed to provide additional insight into the quantitative results. Following the individual and focus groups interviews the qualitative data was coded based on thematic analysis. Themes emerged were: 1) self concept as learner; 2) motivation for learning; and 3) using concept mapping for writing.

The first theme, self concept as learner, looks at participants' perception of themselves as learners. At the beginning of the course, students indicated that they mainly prefer teacher-centered learning approach. This was signified by their responses to the question "How would you describe yourself as a learner?" One student stated that "I understand that there are so many innovative ways to learn but I prefer a lecture where the teacher is the most active person and answers my questions immediately. I prefer learning this way because my whole life I've been taught to think that way." Responses from the post-intervention interviews suggest that concept mapping increased students awareness and reinforced their views of their personal identity as active learners. One student stated that "using concept mapping made me more aware of how I can intentionally make my learning more effective. I value the use of concept mapping and how it can make such a difference in my future education".

The second theme, motivation for learning, concerns about participants' perspective of their motivation. The responses received in pre and post-intervention interviews did differ. The majority of respondents, at the pre-intervention interviews, reveal external motivation for learning (e.g., achieving good grades, social status) as evidenced by their responses to the question "What motivates you to learn?" One student indicated that "Having very good grades in classes and a high GPA, I want to further my studies to doctoral degree. Having a PhD will increase my career options and raise my social status” Responses from the post-intervention interviews suggest that students become more motivated internally as they implemented concept mapping in their learning. One student indicated that "I

Table 1.

Comparison between the pre and post-intervention scores on the ARRP.

\begin{tabular}{cccccccc}
\hline Variable & Measure & $\mathrm{N}$ & Mean & $\mathrm{SD}$ & $t$-value & $d f$ & $p$-value \\
\hline \multirow{2}{*}{ ARRP Scores } & Pre-test & 29 & 26.48 & 7.03 & & & \\
& Post-test & 29 & 81.03 & 8.06 & & & \\
\hline
\end{tabular}

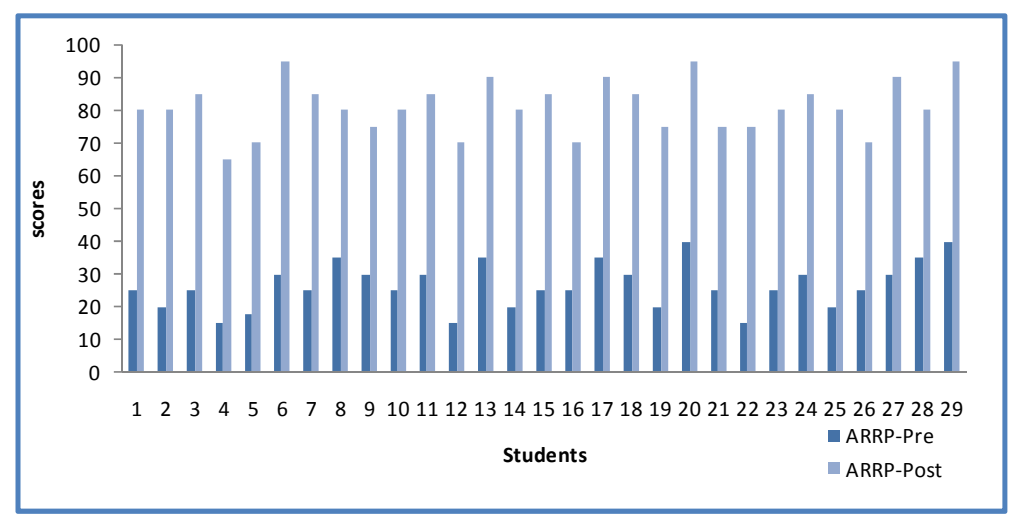

Figure 1.

Comparison of participants' pre- and post-scores on ARRP. 
found using concept mapping to be very challenging and rewarding at the same time. I enjoy reading more and how I put my opinions across while creating concept maps that really make reading and learning meaningful”.

The third theme, using concept mapping for writing, is based on the claim that concept mapping might aid the writing process. In response to the question "Did the concept mapping aid you in writing your proposal?” the students stated that concept mapping helped them to organize their knowledge and writing. The following quote is representative of the comments made by students who stated they benefit from concept mapping: "Mapping concepts from different reading materials helped me to make sense out of literature and to identify the major themes to be covered in my proposal. I also believe that concept mapping helped me in studying different opinions and ideas which situate my research questions and design within the literature I reviewed". The least enthusiastic support for using concept mapping by the students, who were struggling with the mapping
Table 2.

Comparison between the pre and post-intervention scores on the SDLS.

\begin{tabular}{cccccccc}
\hline Variable & Measure & $\mathrm{N}$ & Mean & $\mathrm{SD}$ & $t$-value & $d f$ & $p$-value \\
\hline \multirow{2}{*}{ DLS scores } & Pre-test & 29 & 212.4 & 13.78 & 2.626 & 28 & 0.014 \\
& Post-test & 29 & 213.0 & 13.58 & & & \\
\hline
\end{tabular}

Table 3.

Comparison between the pre and post-intervention scores on the SDLS and APRP.

\begin{tabular}{ccccccc}
\hline Measure & Variable & $\mathrm{N}$ & Mean & SD & $r$-value & $p$-value \\
\hline \multirow{2}{*}{ Pre-scores } & ARRP & 29 & 26.48 & 7.033 & & \\
& SDLS & 29 & 212.4 & 13.78 & & 0.692 \\
\multirow{2}{*}{ Post-scores } & ARRP & 29 & 81.03 & 8.059 & & \\
& SDLS & 29 & 213.3 & 13.58 & 0.670 & 0.000 \\
\hline
\end{tabular}

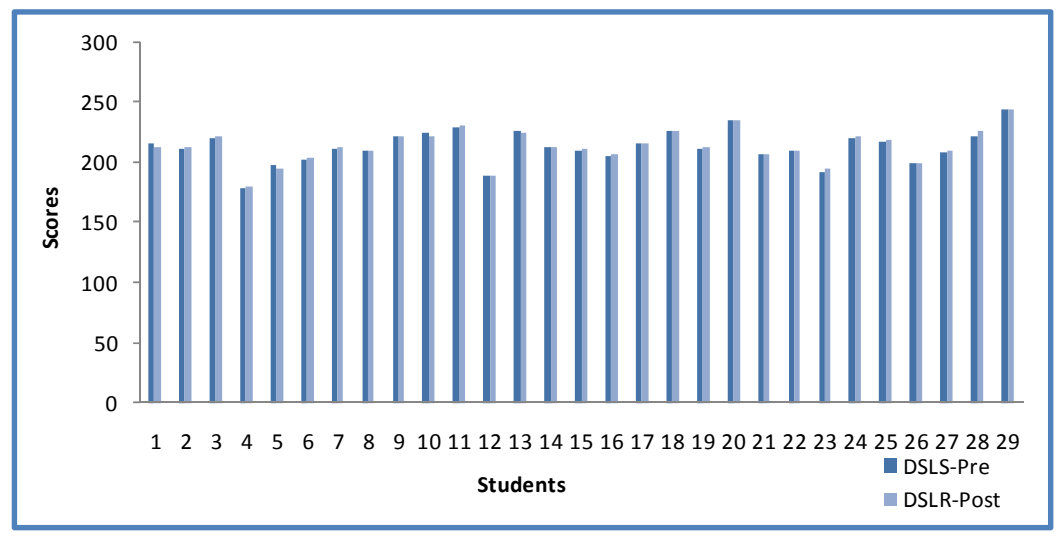

Figure 2.

Comparison of participants' pre- and post-intervention scores on DSLS.
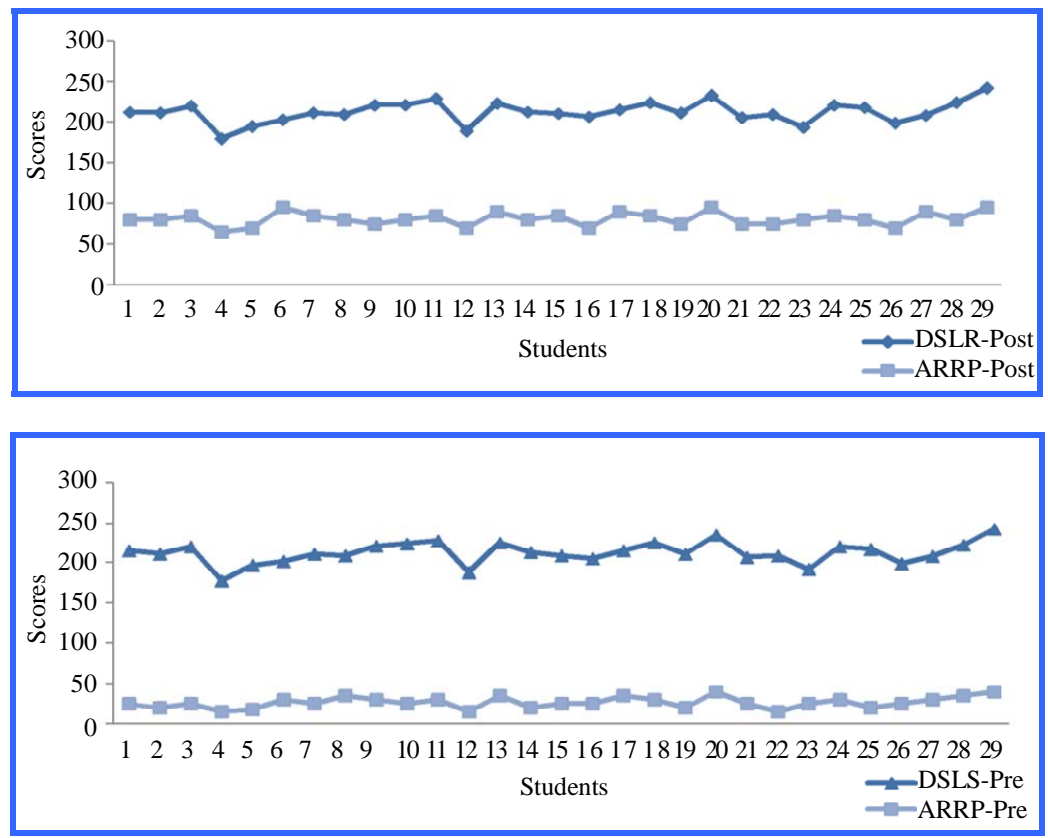

Figure 3.

Correlation between students' scores on the SDLS and ARRP in the pre- and post-intervention. 
procedure, was reflected in the statement "Not really, although concept mapping helped me to identify concepts they should link with others, but it was difficult to find the right word to link the different concepts. Instead of understanding the material, I was focusing on finding linking words that made sense to the concepts. I believe that concept mapping helped me in finding key ideas for writing my proposal, but I need to have an expert opinion and support during the writing process of my proposal”.

Pre and post-intervention concept maps were compared in a qualitative manner. Evaluation of concept maps was based on several characteristics including number of nodes, propositions, cross-links, structure classification, and overall perceptions. Data from analyzing the post-intervention concept maps indicate that there is an improvement in concept map quality over time. This result is in line with previous research (e.g., Fisher et al., 2000; Jacobs-Lawson \& Hershey, 2002) showing that the level of concept map's complexity enhanced with practice.

I further wanted to understand how concept mapping influence students' research proposal development and writing. Therefore, using "soft" data measure classification, I classified the students in groups based on their performance on the post-concept map and the ARRP final scores. There were three categories of students' performance as follows: 1) students who created rich maps and produced good proposals; 2) students who created average maps and produced average proposals; and 3) students who created average maps and produced good proposals. Results of the classifications are presented in Table 5.

The result regarding group $\mathrm{C}$ was not predicted, I was expecting that all the students who created rich maps will also produced good proposals. I was wrong, there were five students who performed well above average on the APRP but their maps contain less information and detail than the maps of other students who produced good proposals. One important question came to my mind: How did my students decide the amount of information to put in their maps? I, to find an answer to my question, contacted three students and set up interviews with them. The three students were not chosen randomly, they were selected from each group. Students' responses to my question were interesting and crystallizing moment for me to understand their maps. All the three students thought that their maps are readable and useful as they tried to include all the information that they think they will need. It is clear that my students did what I have told them to do. They use their maps as highly personal learning tools to understand, remember, or summarize information. The student from group A (S. A.) said that "concept mapping is a useful way to understand by tying together all the new information with what I had learnt”. The student from group B (N. A.) used concept mapping to summarize information, she state "I primarily use concept mapping to summarize information that I have gathered and is important for my subject”. The student from group $\mathrm{C}$, which is the group I was deeply concerned about, (B. H.) declared that concept mapping had helped greatly in defining and writing her research proposal. I placed her map on the table and asked how did this help? She pointed at the map and said "those links and different layers let me see the big picture and remember. It's surprising how much I forget. I think concept mapping is a good tool for reviewing and remembering. My map only include the key concepts that I need to remember the information". I concluded from the students' comments about their maps that the strength of the concept mapping is not only the amount of information (number of nodes), but also how it sparks in the mind of the map creator. There was no student who could created rich map and produced average proposal which indicate the importance of concept mapping in the process of creating a concrete research proposal. Finally, I was pleased to find that $79 \%$ of the students had produced good proposals using concept mapping as a learning strategy.

\section{Conclusion}

In general, the post-intervention assessment data point toward positive changes. All students developed significantly

Table 4.

Mean scores of course and faculty evaluation survey.

\begin{tabular}{lc}
\hline \multicolumn{1}{c}{ Classes } & Mean score \\
\hline Classes throughout the University & 3.83 \\
Classes throughout the College of Education & 3.97 \\
Classes throughout the Department of Special Education & 3.91 \\
SPED 520 Class & 4.36 \\
\hline
\end{tabular}

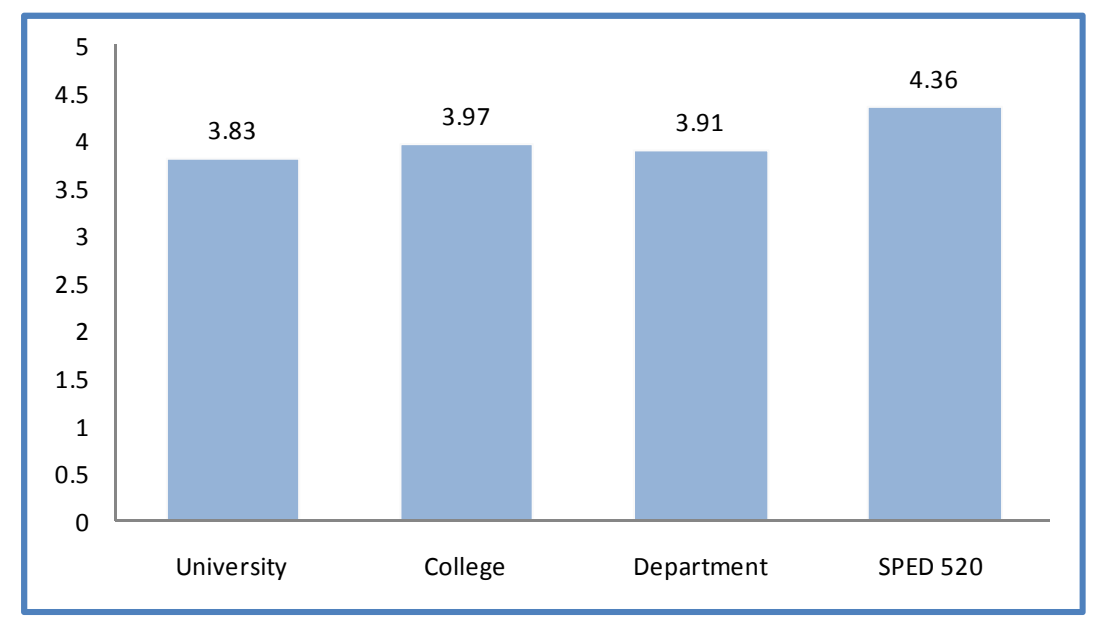

Figure 4.

Mean scores of course and faculty evaluation survey. 
Table 5.

Students' classifications based on their performance on the post-concept map and the ARRP final scores.

\begin{tabular}{|c|c|c|c|c|c|}
\hline \multirow{2}{*}{ Group } & \multirow{2}{*}{$\begin{array}{l}\text { No. of } \\
\text { students }\end{array}$} & \multicolumn{4}{|c|}{$\begin{array}{l}\text { Examples of student performance } \\
\text { (post-intervention scores) }\end{array}$} \\
\hline & & Student & Post-map & ARRP & Students' Comments \\
\hline A & 18 & S. A. & 88 & 95 & $\begin{array}{c}\text { Maps were used } \\
\text { to understand information. }\end{array}$ \\
\hline B & 6 & N. A. & 63 & 78 & $\begin{array}{l}\text { Maps were used } \\
\text { to remember information. }\end{array}$ \\
\hline C & 5 & B. $\mathrm{H}$. & 65 & 96 & $\begin{array}{l}\text { Maps were used to } \\
\text { summarize information. }\end{array}$ \\
\hline
\end{tabular}

more concrete research proposals. They also created more complex concept maps and their scores on SDLRS were increased. Findings from analyzing qualitative data suggest that using concept mapping assist and motivate students to generate more concepts and assimilate the previous knowledge with newly generated concepts. This conclusion backed by Novak and Canas argument that "while at first glance concept maps may appear to be just another graphic representation of information, understanding the foundations for this tool and its proper use will lead the user to see that this is truly a profound and powerful tool” (2006: p. 31). I also believe that using concept mapping develop tendencies for self-directed learning among my students. However, results should be interpreted with caution due to limitations pertaining to the design and participants. Further research should be conducted to implement concept mapping in higher education as I believe this approach aid learners and teachers in reshaping their knowledge in progress and meaningful ways. Finally, not only the results, but the whole experience I had during this study as a teacheraction researcher has taught me to value meaningful education more.

\section{Acknowledgements}

I would like to thank the Deanship of Scientific Research at King Saud University for supporting this research financially.

\section{REFERENCES}

Ackoff, R. (1989). From data to wisdom. Journal of Applied Systems Analysis, 16, 3-9.

Ausubel, D. (1968). Educational psychology: A cognitive view. New York: Holt, Rinehart and Winston.

Bellinger, G. (2004). Knowledge management-Emerging perspectives. (URL last checked 23 August 2011).

http://www.systems-thinking.org/kmgmt/kmgmt.htm

Bergman, M. (2008). Advances in mixed methods research theories and applications. Thousand Oaks, CA: Sage.

Cañas, A., Coffey, J., Carnot, M., Feltovich, P., Hoffman, R., Feltovich, J., \& Novak, J. (2003). A summary of literature pertaining to the use of concept mapping techniques and technologies for education and performance support. The Institute for Human and Machine Cognition. (URL last checked 29 June 2005).

http://www.ihmc.us/users/acanas/Publications/ConceptMapLitReview/ IHMC\%20Literature\%20Review\%20on\%20Concept\%20Mappingpdf

Candy, P. (1991). Self-direction for lifelong learning: A comprehensive guide to theory and practice. San Francisco, CA: Jossey-Bass Publishers.

Carr, W., \& Kemmis, S. (1983). Becoming critical: Knowing through action research. Geelong, VIC: Deakin University Press.

Charmaz, K. (2006). Constructing grounded theory: A practical guide through qualitative analysis. Thousand Oaks, CA: Sage.

Creswell, J. (2008). Educational research: Planning, conducting, and evaluating quantitative and qualitative research. Upper Saddle River, NJ: Merrill Prentice Hall.

Denzin, K., \& Lincoln, Y. (2005). The SAGE handbook of qualitative research. Thousand Oaks, CA: Sage. doi:10.1177/1468794105047237

Fisher, K., Wandersee, D., \& Moody, D. (2000). Mapping biology knowledge. The Netherlands: Kluwer Academic Publishers.

Garrison, D. (1997). Self-directed learning: Toward a comprehensive model. Adult Education Quarterly, 48, 18-33. doi:10.1177/074171369704800103

Gee, J. (2005). An introduction to discourse analysis: Theory and method. New York: Routledge.

Grow, G. (1991). Teaching learners to be self-directed: A stage approach. Adult Education Quarterly, 41, 125-149. doi:10.1177/0001848191041003001

Guglielmino and Associates (2004). Self-directed learning readiness scale. (URL last checked 7 January 2011). http://www.guglielmino934.com/prod 01.htm

Jacobs-Lawson, J., \& Hershey, D. (2002). Concept maps as an assessment tool in psychology courses. Teaching of Psychology, 29, 25-29. doi:10.1207/S15328023TOP2901_06

Knowles, M. (1975). Self-directed learning. New York: Association Press.

Lambert, L., Walker, D., Zimmerman, D., Cooper, J., Lambert, M., Gardner, M., \& Szabo, M. (2002). The constructivist leader. New York: Teachers College Columbia University.

Mertler, C. (2006). Action research: Teachers as researchers in the classroom (2nd ed.). Thousand Oaks, CA: Sage.

Mordock, K., \& Krasny, M. (2001). Participatory action research: A theoretical and practical framework for EE. Journal of Environmental Education, 32, 15-20. doi:10.1080/00958960109599140

Novak, J. (1977). A theory of education. Ithaca, NY: Cornell University Press.

Novak, J. (1998). Learning, creating, and using knowledge. NJ: Lawrence Erlbaum Association.

Novak, J., \& Gowin, D. (1984). Learning how to learn. New York: Cambridge University Press. doi:10.1017/CBO9781139173469

Novak, J., \& Cañas, A. (2006). The theory underlying concept maps and how to construct them (Tech. Rep. IHMC CmapTools 2006-01). Pensacola, FL: Florida Institute for Human and Machine Cognition. (URL last checked 12 June 2012).

http://cmap.ihmc.us/Publications/ResearchPapers/TheoryUnderlying ConceptMaps.pdf

Roberts, G., \& Dick, B. (2003). Emancipatory design choices for action research practitioners. Journal of Community and Applied Social Psychology, 13, 486-495. doi:10.1002/casp.753

Rowley, J. (2007). The wisdom hierarchy: representations of the DIKW hierarchy. Journal of Information Science, 33, 163-180. doi:10.1177/0165551506070706

Somekh, B. (2006). Constructing inter-cultural knowledge and understanding through collaborative action research. Teachers and Teaching: Theory and Practice, 12, 87-106. doi:10.1080/13450600500365460

Taylor, S., Rudolph, J., \& Foldy, G. (2008). Teaching reflective practice in the action science/action inquiry tradition: Key stages, concepts and practices. In Reason and Bradbury (Eds.), The SAGE handbook of action research: Participative inquiry and practice (pp. 656-668). Thousand Oaks, CA: Sage.

Teddlie, C., \& Tashakkori, A. (2009). Foundations of mixed methods research: Integrating quantitative and qualitative approaches in the social and behavioral sciences. Thousand Oaks, CA: Sage.

Zins, C. (2007). Conceptual approaches for defining data, information, and knowledge. Journal of the American Society for Information Science and Technology, 58, 479-493. doi:10.1002/asi.20508 